J. Lake Sci. (湖泊科学), 2019, 31(3): 656-666

DOI 10. 18307/2019. 0305

(C) 2019 by Journal of Lake Sciences

\title{
金沙江下游梯级水库对氮、磷营养盐的滞留效应
}

\author{
刘尚武 ${ }^{1}$, 张小峰 ${ }^{* *}$, 吕平毓 ${ }^{2}$, 兰 峰 ${ }^{2}$ \\ (1:武汉大学水资源与水电工程科学国家重点实验室,武汉 430072) \\ (2: 长江上游水环境监测中心, 重庆 400010)
}

\begin{abstract}
摘 要: 氮、磷是水域重要的营养或污染物质,大型水库修建将对江河氮、磷物质的输运产生重要影响. 以金沙江华弹、向 家坝水文站 2006-2016 年实测水质资料为依据, 通过建立污染物浓度与流量比值 (TN/Q、TP/Q) 与含沙量 $(\mathrm{S})$ 的关系式, 对金沙江下游溪洛渡、向家坝梯级水库蓄水前后进出库总氮 ( TN)、总磷 ( TP) 浓度及通量的变化特征进行研究. 结果表 明: ( 1) 华弹站不受蓄水影响, TN 和 TP 浓度在 $0.38 \sim 1.41$ 和 $0.01 \sim 0.73 \mathrm{mg} / \mathrm{L}$ 之间变化, 向家坝站蓄水前 TN 和 TP 浓度在 $0.32 \sim 1.33$ 和 $0.03 \sim 0.42 \mathrm{mg} / \mathrm{L}$ 之间变化, 蓄水后在 $0.35 \sim 1.29$ 和 $0.01 \sim 0.05 \mathrm{mg} / \mathrm{L}$ 之间变化, 蓄水后 $\mathrm{TN}$ 浓度较蓄水前略有 升高, 但 TP 浓度较蓄水前约降低 $75 \%$; (2) 蓄水前华弹站 $\mathrm{TN}$ 浓度与向家坝站基本接近, TP 浓度总体低于向家坝站, 蓄水 后华弹站 $\mathrm{TN}$ 浓度低于向家坝站, TP 浓度明显高于向家坝站; (3) 金沙江 $\mathrm{TN}$ 以硝态氮 $\left(\mathrm{NO}_{3}^{-}-\mathrm{N}\right)$ 为主, 占 $\mathrm{TN}$ 浓度的 $67.3 \% \sim 91.8 \%$; (4) 两站的 TN 浓度随流量和含沙量变化较小, TP 浓度与流量和含沙量均呈正相关关系; (5) 华弹站 TN、 $\mathrm{TP}$ 年通量在 $48357 \sim 135827$ 和 4720 14163 $\mathrm{t}$ 之间变化, 年均值分别为 90337 和 $8932 \mathrm{t}$, 向家坝站蓄水前后 $\mathrm{TN}$ 年通量在 64232 130966 和 71675 149647 t 之间变化, 蓄水后通量总体高于蓄水前, TP 年通量在 8851 18624 和 $3131 \sim 7300 \mathrm{t}$ 之间 变化, 蓄水后通量远低于蓄水前; (6) 水库蓄水对出库 TN 浓度与通量无明显影响, 但 $\mathrm{TP}$ 浓度与通量较蓄水前明显降低, 其中通量年均滞留率约为 $67.0 \%$.
\end{abstract}

关键词: 金沙江; 总氮; 总磷;滞留效应;梯级水库

\section{Effects of cascade reservoirs in the lower reaches of Jinsha River on nitrogen and phos- phorus retention}

\author{
LIU Shangwu ${ }^{1}$, ZHANG Xiaofeng ${ }^{1 * *}$, LV Pingyu ${ }^{2} \&$ LAN Feng ${ }^{2}$ \\ (1: State Key Laboratory of Water Resources and Hydropower Engineering Science, Wuhan University, Wuhan 430072, P.R. \\ China) \\ (2: Water Environment Monitoring Office on the Yangtze River, Chongqing 400010, P.R.China)
}

\begin{abstract}
Nitrogen and phosphorus were important nutrients or pollutants in water. The construction of large reservoirs would have a profound impact on their transmission characteristics. Based on the measured water quality data of Huatan and Xiangjiaba hydrological stations from 2006 to 2016 in Jinsha River, the relationships between TN/Q, TP/Q and sediment concentration (S) were established, and the change characteristics of total nitrogen (TN) and total phosphorus (TP) concentrations and flux before and after Xiluodu and Xiangjiaba cascade reservoirs were studied. The result showed as follow: (1) The concentrations of TN and TP were $0.38-1.41 \mathrm{mg} / \mathrm{L}$ and $0.01-0.73 \mathrm{mg} / \mathrm{L}$ in Xiangjiaba Station, the concentrations of TN and TP were $0.32-1.33 \mathrm{mg} / \mathrm{L}$ and $0.03-0.42 \mathrm{mg} / \mathrm{L}$ before impoundment, the concentrations of TN and TP were $0.35-1.29 \mathrm{mg} / \mathrm{L}$ and $0.01-0.05 \mathrm{mg} / \mathrm{L}$ after impoundment in Xiangjiaba Station, the concentration of TP decreased by about 75\% compared with that before impoundment. (2) The concentration of TN in Huatan Station was close to Xiangiaba Station, and the concentration of TP in Huatan Station was less than that in Xiangjiaba Station before impoundment. But after impoundment, the concentration of TN in Huatan Station was less than that in Xiangjiaba Station, and the concentration of TP in Huatan Station was obviously more than that in Xiangjiangba Sation.
\end{abstract} (3) The concentration of TN in Jinshajiang River was dominated by $\mathrm{NO}_{3}^{-}-\mathrm{N}$, accounting for $67.3 \%-91.8 \%$. (4) The concentration

* 国家重点研发计划项目(2016YFA0600901) 资助. 2018-08-03 收稿;2018-10-24 收修改稿. 刘尚武( 1994 ), 男, 硕士研究生;E-mail:502870518@qq.com.

** 通信作者;E-mail: zhangxfwhuee@ 263.net. 
of TN had a little relationship with flow and sediment concentration, and the concentration of TP had positive relationships with flow and sediment concentration. (5) The fluxes of TN and TP in Huatan Station were 48357-135827 and 4720-14163 t, with the mean values of 90337 and $8932 \mathrm{t}$, respectively. The flux of TN were 64232-130966 and 71675-149647 t, and the flux of TP were 8851-18624 and 3131-7300 t before and after impoundment in Xiajiaba Station. (6) TN concentration and discharge had no significant effect after reservoir impoundment, but TP concentration and flux were significantly reduced, the annual retention rate was about $67.0 \%$.

Keywords: Jinsha River; total nitrogen; total phosphorus; retention effect; cascade reservoir

“陆一海”物质输移是维持海洋生态系统的重要过程, 在该过程中河流起到主要的“传送带” 作用. 据估 计, 全球每年经河流进人海洋的陆源营养物质约 200 亿 $\mathrm{t}^{[1]}$. 然而河流筑坝工程等人类活动, 使得这一输送 过程日益受到破坏:一方面, 河流筑坝形成水库将引起河流水动力学条件的改变, 导致颗粒物迁移、输运等 过程发生显著变化; 另一方面, 水库效应还引起河流水流变缓、透明度增加, 导致浮游藻类生物量增加, 从而 使溶解态营养盐从河流中去除, 临时或永久性地留存于库中, 限制了河流向下游的物质输出 ${ }^{[2]}$. 从而给下游 河流及海洋带来不良的生态效应, 因此研究大坝对营养物质的滞留效应具有重要的科学和现实意义.

氮、磷等营养元素是生物地球化学循环的物质基础, 同时又是引起水体富营养化的主要元素, 国内外学 者对水库氮、磷营养盐的滞留效应开展了大量研究工作. 研究表明, 法国 Seine 河上游由于水库的建设拦截 了约 $60 \%$ 的人库磷酸盐, 淤积于库区的磷酸盐大部分被沉积物和底栖生物所吸收 ${ }^{[3]}$; 黄河流域由于高强度 的梯级电站开发, 断流和水质恶化现象愈加严重, 其中总磷 (TP) 的输出减少了约 $84 \%^{[4]}$; 长江上游地区建 设了大量闸坝和水库, 以三峡工程为甚, 造成向下游输移的 TP 通量减少了约 $77 \%{ }^{[5]}$; 江西万安水库溶解态 无机氮 (DIN) 年滞留率为 $20 \% \sim 40 \%$, 年均值为 $32.0 \%$, TP 的滞留率有正有负, 在 $-89 \% \sim 80 \%$ 之间变化 ${ }^{[6]}$; 乌江中上游洪家渡、东风和乌江渡 3 座水库总氮 ( TN ) 年均滞留率分别为 $20.2 \% 、 36.0 \%$ 和 $-12.1 \%$, TP 年均 滞留率分别为 $5.4 \% 、 56.5 \%$ 和 $-84.9 \%{ }^{[7]}$. 可见不同水库氮、磷营养盐的滞留效应相差较大.

长江是世界第三、中国第一大河流. 金沙江位于长江上游, 流经青海、西藏、四川、云南 4 省区, 流域面积 约 50 万 $\mathrm{km}^{2}$, 占长江流域面积的 $27.8 \%$, 占长江上游 (宜昌) 流域面积的 $50.0 \%$, 是长江流域主要产流产沙 区 $^{[8]}$ 和营养盐的重要来源区 ${ }^{[9]}$. 随着金沙江下游溪洛渡、向家坝两座超大型水库相继投人使用,其巨大的水 库库容将对金沙江泥沙及氮、磷营养盐的输运产生重要影响. 但目前的研究大多侧重于水沙情势变化方 面 ${ }^{[10-11]}$, 对氮、磷营养盐的影响方面报导较少. 郭宗锋等 ${ }^{[12]}$ 对向家坝库区的主要污染物种类、浓度、时间和 空间变化等进行了分析, 对认识向家坝库区的水质现状有一定意义, 但研究成果尚未涉及到水库对氮、磷营 养盐的滞留影响方面. 考虑到金沙江是长江流域营养盐的重要来源区, 金沙江下游梯级水库对氮、磷的滞留 作用将会对长江上游珍稀鱼类保护区、三峡工程乃至长江中下游和近海水域的生态效应带来重大影响, 因 此开展金沙江下游梯级水库对氮、磷营养盐的滞留效应研究是必要的. 本文根据金沙江溪洛渡、向家坝梯级 水库进出库水文站 2006-2016 年实测水质资料, 分析了溪洛渡、向家坝梯级水库蓄水前后 TN、TP 浓度的动 态变化, 建立了 TN、TP 浓度与流量和含沙量的综合关系式, 以此为基础, 估算了水库蓄水前后进出库 TN、TP 通量的变化和水库滞留效应.

\section{1 材料与方法}

\section{1 研究区概况}

研究区域位于金沙江下游. 金沙江发源于青藏高原唐古拉山脉各拉丹东峰南侧,以石鼓、攀枝花为界分 为上、中、下游. 上游属青藏高原高寒草甸畜牧区, 人烟稀少; 中游位于横断山区中部, 山高谷深, 以林区为 主; 攀枝花以下的金沙江位于横断山区东部, 人口众多, 以农业为主, 坡耕地大面积分布, 分布有已建的向家 坝、溪洛渡以及在建的白鹤滩、乌东德电站四大梯级电站, 是我国主要的水电能源基地. 向家坝电站是金沙 江干流梯级开发的最下一级, 距宜宾约 $33 \mathrm{~km}$, 控制流域面积约 45.88 万 $\mathrm{km}^{2}$, 正常蓄水位 $380 \mathrm{~m}$, 总库容 51.63 亿 $\mathrm{m}^{3}$, 库容 9.03 亿 $\mathrm{m}^{3}, 2012$ 年 10 月起开始蓄水发电; 溪洛渡电站位于向家坝电站上游, 距向家坝电 站约 $157 \mathrm{~km}$, 控制流域面积约 45.44 万 $\mathrm{km}^{2}$, 正常蓄水位 $600 \mathrm{~m}$, 总库容 126.7 亿 $\mathrm{m}^{3}$, 调节库容 64.6 亿 $\mathrm{m}^{3}$, 2013 年 5 月开始蓄水发电. 金沙江下游溪洛渡、向家坝电站位置见图 1. 


\section{2 采样地点}

采样地点位于华弹水文站和向家坝水文站. 华弹站为溪洛渡、向家坝梯级水库的人库控制站, 位于四川 省宁南县华弹镇 $\left(26^{\circ} 55^{\prime} \mathrm{N}, 102^{\circ} 53^{\prime} \mathrm{E}\right)$, 控制流域面积 $42.59 \times 10^{4} \mathrm{~km}^{2}$, 设于 1939 年, 2015 年起该站流量、泥沙 停测, 只保留水位、水质观测项目, 因与下游白鹤滩站集水面积仅相差 $1 \%$, 故 2015 年后该站的水沙资料由 白鹤滩站代替. 向家坝站为溪洛渡、向家坝梯级水库的出库控制站, 位于向家坝水库下游 $2 \mathrm{~km}$ 处 $\left(28^{\circ} 38^{\prime} \mathrm{N}\right.$, $\left.104^{\circ} 24^{\prime} \mathrm{E}\right)$ ，控制流域面积 $45.88 \times 10^{4} \mathrm{~km}^{2}$,于 2006 年设立. 各水文站位置见图 1.

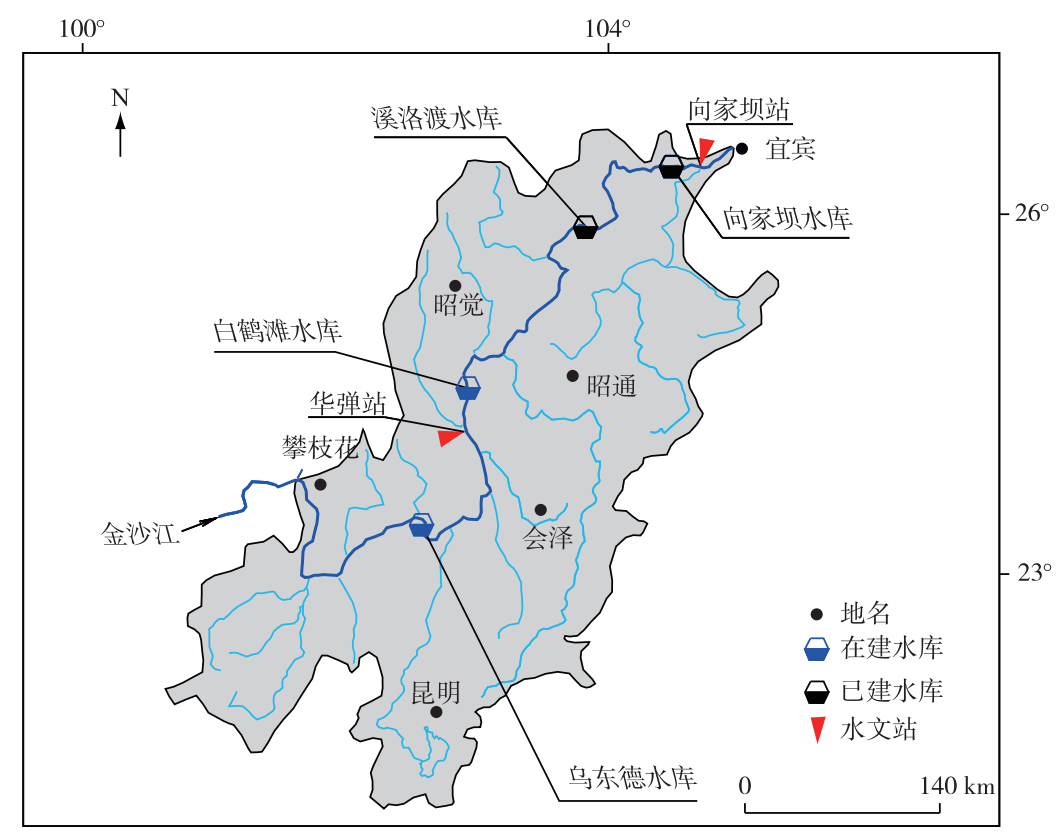

图 1 金沙江下游水系和水文站

Fig. 1 Layout of downstream Jinsha Basin and hydrological stations

\section{3 资料采集及分析方法}

本文采用的水沙数据来自长江委水文局历年水文整编成果, 水质资料来源于长江上游水环境监测中心 历年整编成果. 华弹站、向家坝站水质监测频率为每月一次, 时间主要为各月的上旬或中旬, 观测时取水文 断面的左中右 3 条垂线, 采取缆道采样器采集样品, 每条垂线在水面下 $0.5 \mathrm{~m}$ 处布设 1 个测点. 水样采集后 经自然澄清 $30 \mathrm{~min}$ 后, 取上层水样后存放到专用容器, 加保存剂并冷藏, $12 \mathrm{~h}$ 内送达实验室分析. 其中 TP 浓 度采用钼酸铵分光光度法分析 (GB 11893-1989), 检出限为 $0.01 \mathrm{mg} / \mathrm{L}$; TN 浓度采用碱性过硫酸钾消解紫 外分光光度法分析 ( HJ 636- 2012), 检出限为 $0.05 \mathrm{mg} / \mathrm{L}$; 亚硝酸盐氮 $\left(\mathrm{NO}_{2}^{-}-\mathrm{N}\right)$ 浓度采用分光光度法分析 ( GB 7493-1987), 检出限为 $0.003 \mathrm{mg} / \mathrm{L}$; 硝酸盐氮 $\left(\mathrm{NO}_{3}^{-}-\mathrm{N}\right)$ 浓度采用紫外分光光度法分析 ( SL 84-1994), 检出限为 $0.08 \mathrm{mg} / \mathrm{L}$; 氨氮 $\left(\mathrm{NH}_{3}-\mathrm{N}\right)$ 浓度采用纳氏试剂分光光度法分析 $(\mathrm{HJ} 535-2009)$, 检出限为 0.025 $\mathrm{mg} / \mathrm{L}$.

\section{4 数据处理}

使用 Excel 软件对数据进行统计和处理. 由于各站水质资料系列长短不一, 最短为向家坝站 2006-2016 年系列, 为保证资料的一致性, 本次将资料分析年限统一至 2006-2016 年. 为便于蓄水前后成果对比, 将实 测资料划分为 2006-2012 年和 2013-2016 年两个时段; 另将年内 6-9 月划分为汗期, 4、5、10、11 月划分 为平水期, $1-3$ 月、 12 月划分为枯水期. 


\section{2 结果与讨论}

\section{1 蓄水前后水沙关系变化}

金沙江下游是金沙江流域的多水多沙区 ${ }^{[13]}$, 也是典型的干热河谷区 ${ }^{[14]}$, 水土流失现象严重, 是长江流 域来水来沙的重要组成部分. 经统计, 蓄水前后华弹站、向家坝站径流量和输沙量年内分配差异较小, 都主 要集中在汛期,其中主汛期径流量占年径流量的 78\%, 输沙量占年输沙量的 $97 \%$. 图 2A 是华弹站、向家坝站 逐年径流量、输沙量变化过程线图. 为分析两站径流量、输沙量变化趋势, 采用 Spearman 秩次检验法 ${ }^{[15]}$, 其

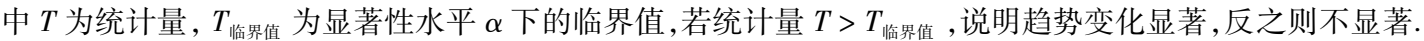

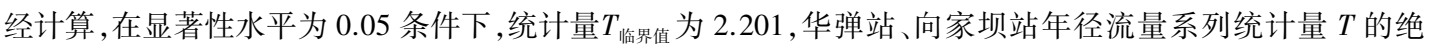
对值分别为 0.217 和 0.515 , 年输沙量系列统计量 $T$ 的绝对值分别为 1.250 和 2.593 , 说明华弹站径流量和输 沙量无显著性变化趋势, 向家坝站径流量也无显著性变化趋势,但输沙量减少趋势显著. 经统计, 向家坝站 2006- 2012 年年均输沙量为 13204 万 $\mathrm{t}, 2013-2016$ 年年均输沙量仅为 175 万 $\mathrm{t}$, 约减少 $98.7 \%$; 年均含沙量 也由蓄水前的 $0.981 \mathrm{~kg} / \mathrm{m}^{3}$ 减少到蓄水后的 $0.0135 \mathrm{~kg} / \mathrm{m}^{3}$, 约减少了 $98.6 \%$. 向家坝站输沙量的锐减主要与 溪洛渡和向家坝水库蓄水后流速较小、泥沙大量淤积有关.

\section{2 蓄水前后氮、磷浓度的动态变化}

2.2.1 TN 和 TP 多年平均浓度 据实测资料统计, 2006- 2016 年华弹站 TN 和 TP 浓度在 $0.380 \sim 1.410$ 和 $0.010 \sim 0.730 \mathrm{mg} / \mathrm{L}$ 之间变化,多年均值分别为 0.731 和 $0.077 \mathrm{mg} / \mathrm{L}$; 向家坝站 TN 和 TP 浓度在 $0.320 \sim 1.290$ 和 $0.010 \sim 0.420 \mathrm{mg} / \mathrm{L}$ 之间变化, 多年均值分别为 0.735 和 $0.085 \mathrm{mg} / \mathrm{L}$. 与国内主要河流 $1980 \mathrm{~s}$ 的 TN、TP 浓 度 ${ }^{[16]}$ 比较, 金沙江下段 TN、TP 浓度明显低于黄河, 与珠江基本一致, TN 浓度略高于长江, TP 浓度略低于长 江; 与世界河流背景值 ${ }^{[17]}$ 比较, TN 、TP 浓度均高于世界河流背景值 $($ 表 1).

表 1 金沙江下段和其他主要河流总氮和总磷多年平均浓度

Tab.1 Average years concentrations of total nitrogen and total phosphorus in the lower of Jinsha River and other main rivers

\begin{tabular}{cccccc}
\hline 指标 & 金沙江 & 黄河 & 长江 & 珠江 & 世界河流背景值 \\
\hline $\mathrm{TN} /(\mathrm{mg} / \mathrm{L})$ & 0.735 & 1.983 & 0.498 & 0.686 & 0.116 \\
$\mathrm{TP} /(\mathrm{mg} / \mathrm{L})$ & 0.085 & 5.652 & 0.166 & 0.070 & 0.025 \\
\hline
\end{tabular}

河流水体中氮营养盐包含无机氮和有机氮两种, 无机氮常以 $\mathrm{NH}_{3}-\mathrm{N} 、 \mathrm{NO}_{2}^{-}-\mathrm{N} 、 \mathrm{NO}_{3}^{-}-\mathrm{N} 3$ 种形态存在, 蓄水 前后多年均值见表 2. 经统计, $\mathrm{NO}_{3}^{-}-\mathrm{N}$ 约占无机氮的 $86.6 \% \sim 94.6 \%$, 是金沙江下游水体无机氮的主要组成部 分; 无机氮总量约占 TN 的 67.3\% 91.8\%, 该比例一般上游小于下游, 蓄水前华弹站约为 $77.6 \%$, 向家坝站约 为 $98.6 \%$; 蓄水后华弹站约为 $88.7 \%$, 向家坝站为约 $97.0 \%$. TP 主要包括 $\mathrm{PO}_{4}^{3-}-\mathrm{P}$ 、有机磷、多磷酸盐氮磷和颗 粒态磷, 由于未对金沙江 TP 的组成进行检测, 故目前尚无相关比例资料. 但相关研究表明 ${ }^{[18]}$, 世界多数大 河中的颗粒态磷占 TP 的 $80 \% \sim 90 \%$.

表 2 蓄水前后氮、磷年均浓度

Tab.2 Annual average concentrations of nitrogen and phosphorus before and after storage

\begin{tabular}{|c|c|c|c|c|c|c|c|c|c|c|}
\hline \multirow{2}{*}{ 水文站 } & \multicolumn{5}{|c|}{ 蓄水前浓度/ $(\mathrm{mg} / \mathrm{L})$} & \multicolumn{5}{|c|}{ 蓄水后浓度/( $\mathrm{mg} / \mathrm{L})$} \\
\hline & $\mathrm{NH}_{3}-\mathrm{N}$ & $\mathrm{NO}_{2}^{-}-\mathrm{N}$ & $\mathrm{NO}_{3}^{-}-\mathrm{N}$ & $\mathrm{TN}$ & $\mathrm{TP}$ & $\mathrm{NH}_{3}-\mathrm{N}$ & $\mathrm{NO}_{2}^{-}-\mathrm{N}$ & $\mathrm{NO}_{3}^{-}-\mathrm{N}$ & $\mathrm{TN}$ & $\mathrm{TP}$ \\
\hline 华弹 & 0.067 & 0.009 & 0.491 & 0.732 & 0.076 & 0.043 & 0.008 & 0.596 & 0.726 & 0.080 \\
\hline 向家坝 & 0.070 & 0.008 & 0.602 & 0.694 & 0.116 & 0.038 & 0.006 & 0.771 & 0.841 & 0.028 \\
\hline
\end{tabular}

2.2.2 年际、年内变化 从图 $2 \mathrm{~B}$ 可以看到华弹站、向家坝站 $\mathrm{TN} 、 \mathrm{TP}$ 浓度年际变化. 为评价蓄水前后两站 $\mathrm{TN}$ 、 $\mathrm{TP}$ 浓度差异是否显著, 采用秩和检验法 ${ }^{[15]}$ 进行分析, 其中 $T$ 为统计量, $T_{\text {旧界值(上限) }}$ 和 $T_{\text {旧界值(下限) }}$ 分别为显著性

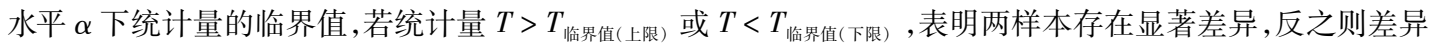


不显著. 经计算, 在显著性水平 0.05 条件下, $T_{\text {临界值(上限) }}=35, T_{\text {临界值(下限) }}=13$, 而华弹站统计量 $T_{\mathrm{TN}}=23 、 T_{\mathrm{TP}}=$ 23 ; 向家坝站统计量 $T_{\mathrm{TN}}=16 、 T_{\mathrm{TP}}=38$, 说明蓄水前后华弹站 $\mathrm{TN} 、 \mathrm{TP}$ 浓度无显著变化, 向家坝站 $\mathrm{TN}$ 浓度也无 显著变化, 但 TP 浓度显著降低. 经统计, 向家坝站 TP 年均浓度由蓄水前的 $0.116 \mathrm{mg} / \mathrm{L}$ 降低至蓄水后的 $0.028 \mathrm{mg} / \mathrm{L}$, 降低了 75\%. 蓄水后随着库区流速的减缓, 大量颗粒态磷沉积到河底, 故出库的向家坝站 TP 浓 度大幅降低.

图 2C 和图 2D 分别为华弹站、向家坝站蓄水前后 $\mathrm{TN} 、 \mathrm{TP}$ 浓度年内变化曲线,表 3 为年内不同时期的平 均浓度, 可见两站 $\mathrm{TN}$ 浓度年内变化不大, 但 TP 浓度年内季节性变化趋势明显, 总体表现为汛期大于枯季, 与郭宗锋等 ${ }^{[12]}$ 的研究成果基本一致. 水库蓄水后, 向家坝站 $\mathrm{TP}$ 浓度较蓄水前大幅度减少, 其中枯水期降低 了 $57.1 \%$, 平水期降低了 $66.7 \%$, 汛期降低了 $84.2 \%$.

(a)

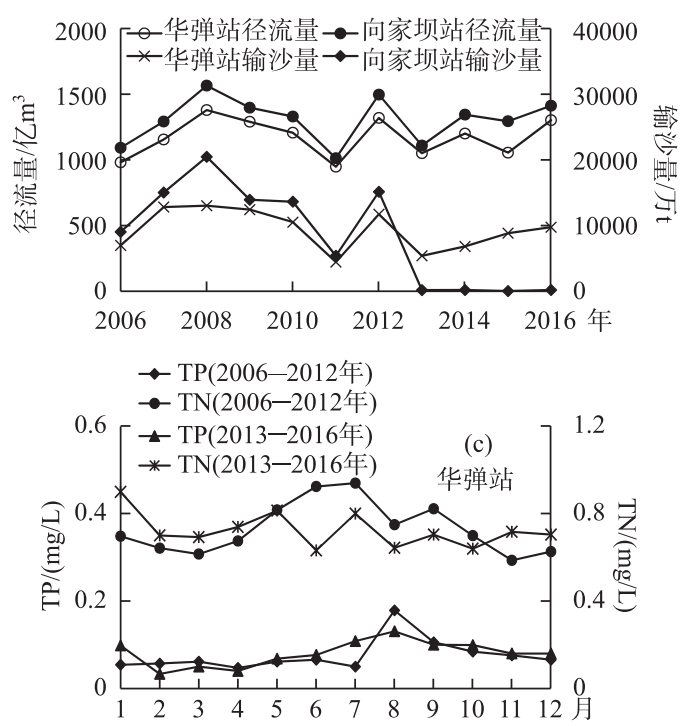

(b)
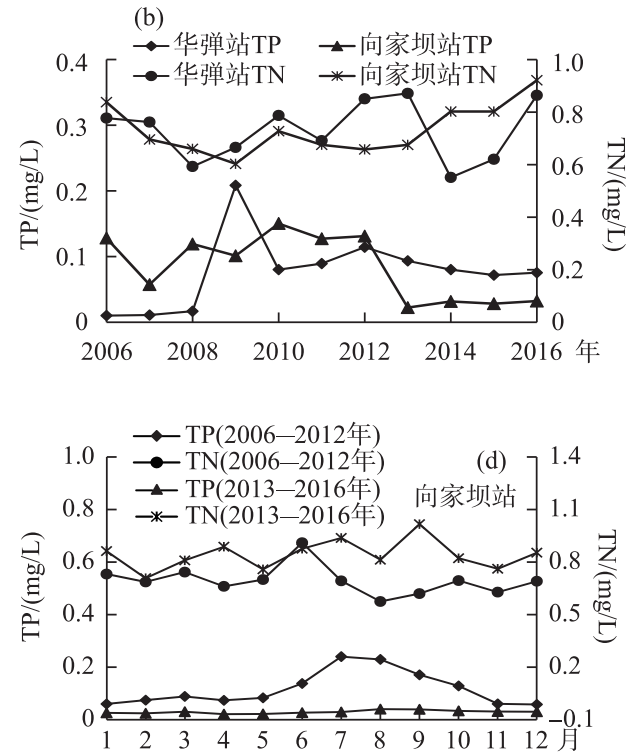

图 2 华弹站、向家坝站年径流量、输沙量年际变化以及总氮和总磷浓度年际、年内变化

Fig. 2 Changes of sediment, discharge, total nitrogen and total phosphorus concentrations in Huatan and Xiangjiaba Stations

2.2 .3 沿程变化 从 $\mathrm{TN}$ 浓度沿程变化来看, 蓄水前华弹站、向家坝站年均 $\mathrm{TN}$ 浓度分别为 0.732 和 $0.694 \mathrm{mg} / \mathrm{L}$, 从上游往下沿程变化不大; 蓄水后年均 $\mathrm{TN}$ 浓度分别为 0.726 和 $0.841 \mathrm{mg} / \mathrm{L}$, 沿程略有升高. 从 $\mathrm{TP}$ 浓度沿程 变化来看, 蓄水前华弹站的 TP 浓度总体低于向家坝站, 沿程升高, 但蓄水后华弹站的 TP 浓度明显低于向家 坝站, 呈沿程降低趋势.

表 3 华弹站、向家坝站蓄水前后总氮和总磷浓度年内变化

Tab.3 Annual variation of total nitrogen and total phosphorus concentrations at Huatan and Xiangjiaba Stations

\begin{tabular}{|c|c|c|c|c|c|c|c|}
\hline \multirow{2}{*}{ 指标 } & \multirow{2}{*}{ 时段 } & \multicolumn{3}{|c|}{ 华弹站 } & \multicolumn{3}{|c|}{ 向家坝站 } \\
\hline & & 枯水期 & 平水期 & 洪水期 & 枯水期 & 平水期 & 洪水期 \\
\hline \multirow[t]{2}{*}{$\mathrm{TN} /(\mathrm{mg} / \mathrm{L})$} & 蓄水前 & 0.633 & 0.730 & 0.858 & 0.695 & 0.694 & 0.699 \\
\hline & 蓄水后 & 0.742 & 0.730 & 0.694 & 0.798 & 0.819 & 0.910 \\
\hline \multirow[t]{2}{*}{$\mathrm{TP} /(\mathrm{mg} / \mathrm{L})$} & 蓄水前 & 0.063 & 0.064 & 0.100 & 0.067 & 0.094 & 0.194 \\
\hline & 蓄水后 & 0.068 & 0.069 & 0.104 & 0.027 & 0.024 & 0.033 \\
\hline
\end{tabular}




\subsection{TN、TP 浓度与流量、含沙量的关系}

2.3.1 与流量的关系 华弹站、向家坝站蓄水前后的 TN 浓度随流量变化较小; 而 TP 浓度变化与流量呈正相 关关系, 其中华弹站蓄水前后无明显变化, 向家坝站蓄水后的 TP 浓度较蓄水前同流量时明显偏低 (图 3). 经相关分析, 华弹站 TP 浓度与流量的相关系数 $R$ 为 0.25 , 向家坝站蓄水前为 0.45 , 蓄水后为 0.38 , 相关性总 体均较差.

一般认为, 河流中 TN 、P 浓度与流量的关系能在一定程度上反映其来源, 若与流量呈负相关, 说明污染 量相对固定, 其大小基本不受流量影响, 表明其主要来自于点源污染; 若与流量呈正相关或先呈正相关后呈 负相关,表明主要来自于面源污染, 因为面源污染主要来源于降雨径流对地表的冲刷, 面源污染量随着径流 量的增大而提高, 但污染物进人河流后, 污染物浓度同时还受到河水稀释的影响, 当地表冲刷作用大于河水 稀释作用时, 污染物浓度与流量呈正相关, 与此相反, 则与流量呈负相关. 若 N、P 浓度与流量变化无关, 则情 况比较复杂, 流域存在点、面共同污染时可能出现此情况，也可能是地表冲刷作用与河水稀释作用基本相同 的缘故 ${ }^{[18]}$. 从 $\mathrm{TN} 、 \mathrm{TP}$ 浓度与流量关系变化看, 金沙江下段 $\mathrm{TN} 、 \mathrm{TP}$ 来源于面源的可能性较大,与郭宗锋等 ${ }^{[12]}$ 的研究结果基本一致.

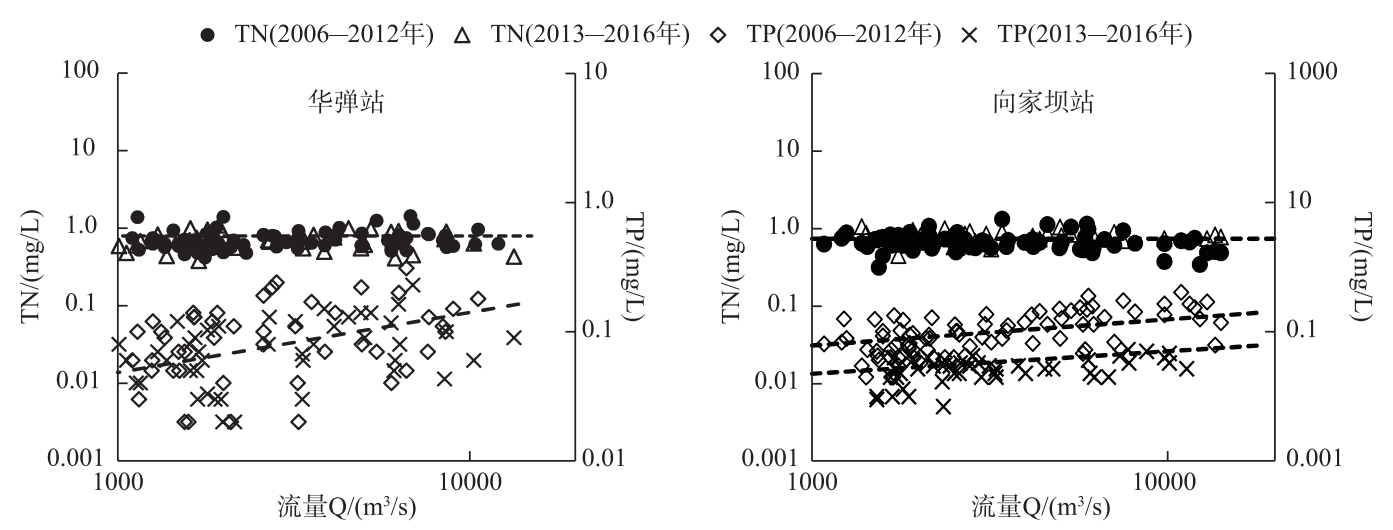

图 3 总氮和总磷浓度与流量的关系

Fig.3 Relation of total nitrogen and total phosphorus concentrations and discharge

2.3.2 与含沙量的关系 泥沙是水体中污染物的主要载体之一, 绝大多数污染物在水体中的输移与泥沙运动 密切相关. 泥沙对水环境的作用具有两重性,一方面泥沙具有吸附作用,使水体中的污染物浓度降低, 从而 改善水质, 起到净化的作用; 另一方面, 当水体条件发生变化后, 泥沙作为污染物的载体, 易发生解吸作用, 可能会导致泥沙颗粒上的污染物重新进人到水相中,引起二次污染.

华弹站、向家坝站 TN 浓度随含沙量变化较小, 但 TP 浓度与含沙量呈正相关关系 (图 4). TN、TP 浓度与 含沙量关系的差异主要是 TN 和 TP 的赋存状态不同造成的. TN 主要以溶解态存在, 故 TN 浓度随含沙量变 化较小; 由于磷与泥沙之间有很强的亲和力, 除水体中存在的颗粒磷外, $\mathrm{PO}_{4}^{3-}-\mathrm{P}$ 、有机酸、多磷酸盐等溶解态 磷也极易与泥沙结合成颗粒态磷, 因此在河流中泥沙为磷的主要载体 ${ }^{[19]}$. 随着流量的增大, 流域输人河流 的泥沙增多,故 TP 浓度也相应升高.

2.3.3 流量与含沙量对 TN、TP 浓度的综合影响 水体中 TN 、 TP 等营养盐浓度的变化受多种因素影响, 主要 包括污染物种类、自身物理化学性质、水环境以及水流的稀释效应、泥沙的吸附及解吸效应等. 在河流动力 学中常将含沙量与流量的比值 (S/Q) 作为衡量河道输沙能力的重要参数, 用于水流输沙及河床演变分 析 ${ }^{[20]}$. 当流量一定时, 含沙量越小, 意味着水流输沙愈不超饱和, 河床将发生冲刷, 反之则发生淤积. 与此类 似, 本文将污染物浓度与流量比值 $(\mathrm{TN} / \mathrm{Q} 、 \mathrm{TP} / \mathrm{Q})$ 作为衡量水流输送污染物能力的参数, 该参数在一定程度 上能反映水流自净能力. 当上游污染来量不变时, 流量越大, 比值越小, 水流稀释能力或自净能力就越强, 反 之则自净能力越弱; 当流量不变时, 上游污染来量越大, 比值越大, 水流自净能力越弱, 反之上游污染来量越 小, 比值越小, 水流自净能力越强. 由图 5 可见, 蓄水前后两站的关系点呈密集带状分布, 趋势明显, TN/Q、 


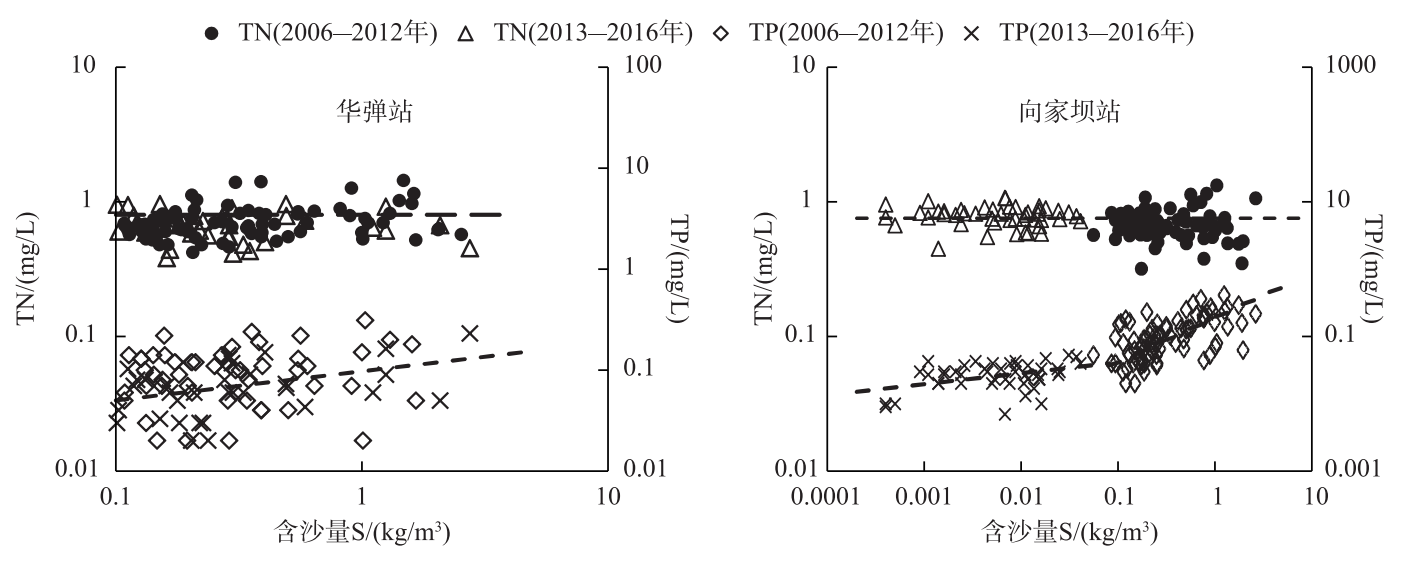

图 4 总氮和总磷浓度与含沙量的关系

Fig.4 Relation of total nitrogen and total phosphorus concentrations and sediment concentration

$\mathrm{TP} / \mathrm{Q}$ 与含沙量 $\mathrm{S}$ 呈负相关, 即含沙量越大, 比值越小, 水体自净能力越强, 反之则水体自净能力越弱, 该关 系在一定程度上反映了泥沙对污染物的吸附作用. 华弹站蓄水前后关系点未发生系统分离, 表明华弹站不 受蓄水影响; 向家坝站蓄水前后关系线明显分为两个系列, 蓄水后的关系线位于蓄水前的左边, 表明向家坝 站受蓄水影响非常明显.
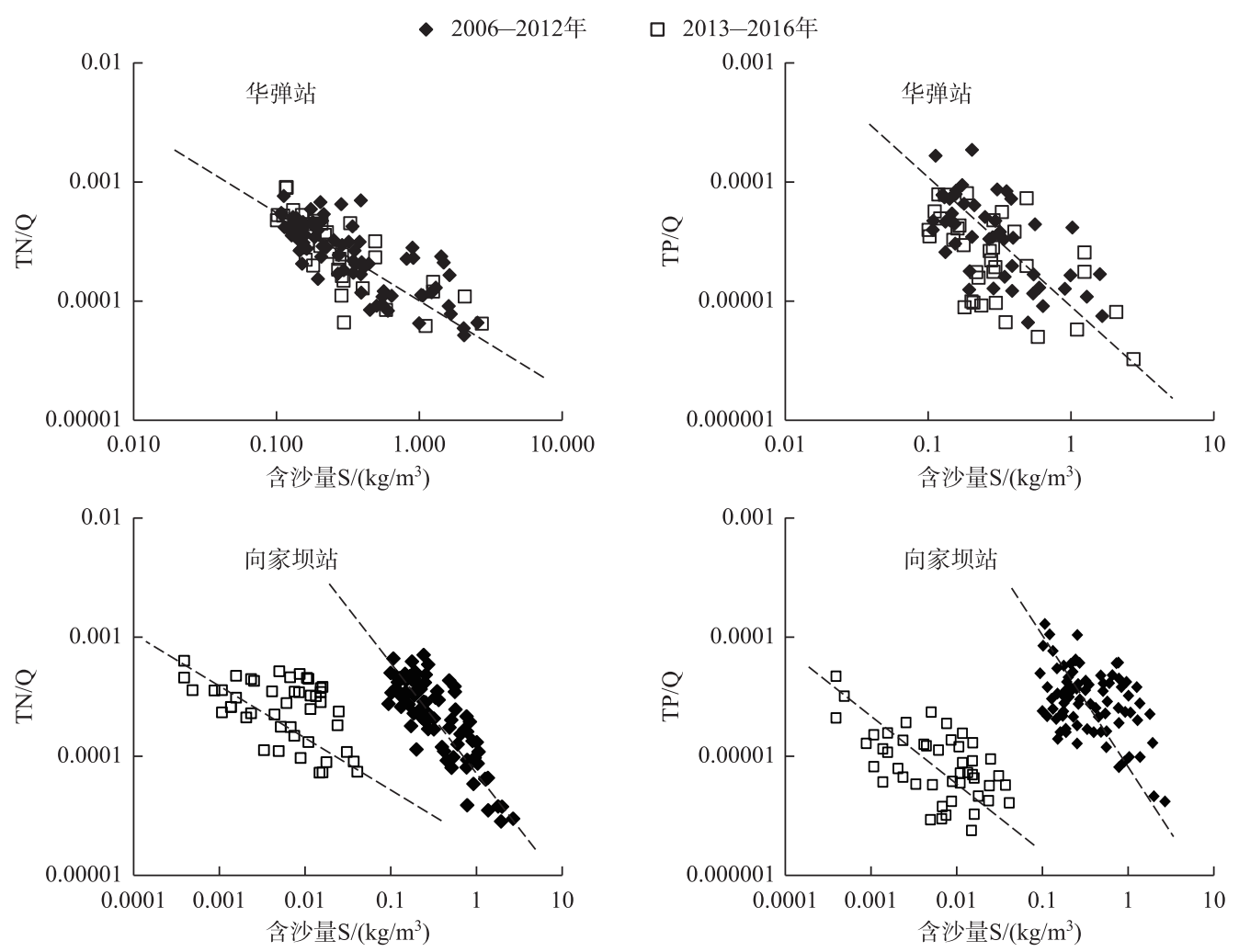

图 $5 \mathrm{TN} / \mathrm{Q}$ 和 $\mathrm{TP} / \mathrm{Q}$ 与含沙量的关系

Fig.5 Relation of TN/Q, TP/Q and sediment concentration 
$\mathrm{TN} / \mathrm{Q} 、 \mathrm{TP} / \mathrm{Q}$ 与含沙量 $\mathrm{S}$ 的关系采用幕函数拟合:

$$
Y=a \cdot S^{b}
$$

式中, $Y$ 为 $\mathrm{TN} 、 \mathrm{TP}$ 浓度与流量 $\mathrm{Q}$ 的比值 $(\mathrm{TN} / \mathrm{Q} 、 \mathrm{TP} / \mathrm{Q})$; $\mathrm{TN} 、 \mathrm{TP}$ 浓度单位为 $\mathrm{mg} / \mathrm{L}$; 流量 $\mathrm{Q}$ 单位为 $\mathrm{m}^{3} / \mathrm{s}$; 含沙 量单位为 $\mathrm{kg} / \mathrm{m}^{3} ; a 、 b$ 分别为公式系数和指数.

由表 4 可见, $Y$ 与含沙量 $S$ 关系的相关系数 $|R|$ 均在 0.6 以上,较 TN、TP 浓度与单独的流量或含沙量相 关系数高, 表明 $\mathrm{TN} / \mathrm{Q}$ 或 $\mathrm{TP} / \mathrm{Q}$ 与含沙量 $\mathrm{S}$ 的关系比单因素更能反映 $\mathrm{TN}$ 、 $\mathrm{TP}$ 的变化规律.

表 4 蓄水前后华弹站、向家坝站 $\mathrm{TN} / \mathrm{Q} 、 \mathrm{TP} / \mathrm{Q}$ 与含沙量 $\mathrm{S}$ 的关系

Tab.4 Correlation of TN/Q, TP/Q and sediment concentration (S) at Huatan and Xiangjiaba Stations before and after storage

\begin{tabular}{|c|c|c|c|c|c|c|c|}
\hline \multirow{2}{*}{ 水文站 } & \multirow{2}{*}{ 种类 } & \multirow{2}{*}{ 时期 } & \multicolumn{3}{|c|}{$\mathrm{TN} / \mathrm{Q} 、 \mathrm{TP} / \mathrm{Q}$ 与 $\mathrm{S}$ 的关系 } & \multicolumn{2}{|c|}{$\mathrm{TN} 、 \mathrm{TP}$ 浓度与 $\mathrm{Q}$ 的关系 $\mathrm{TN} 、 \mathrm{TP}$ 浓度与 $\mathrm{S}$ 的关系 } \\
\hline & & & 系数 $a$ & 指数 $b$ & $|R|$ & $|R|$ & $|R|$ \\
\hline \multirow[t]{2}{*}{ 华弹 } & $\mathrm{TN}$ & 蓄水前后 & $1.094 \times 10^{-4}$ & -0.590 & 0.78 & 0.12 & 0.15 \\
\hline & $\mathrm{TP}$ & 蓄水前后 & $9.967 \times 10^{-6}$ & -0.746 & 0.67 & 0.25 & 0.22 \\
\hline \multirow[t]{4}{*}{ 向家坝 } & $\mathrm{TN}$ & 蓄水前 & $7.16 \times 10^{-5}$ & -0.930 & 0.83 & 0.17 & 0.06 \\
\hline & & 蓄水后 & $1.843 \times 10^{-5}$ & -0.439 & 0.65 & 0.14 & 0.03 \\
\hline & $\mathrm{TP}$ & 蓄水前 & $8.03 \times 10^{-6}$ & -1.108 & 0.61 & 0.48 & 0.42 \\
\hline & & 蓄水后 & $4.25 \times 10^{-7}$ & -0.571 & 0.64 & 0.37 & 0.33 \\
\hline
\end{tabular}

\section{4 通量估算及滞留效应}

2.4.1 出、入库通量估算 理论上 TN、TP 在时段 $T$ 内通过河流某断面的通量为:

$$
M=\int_{0}^{T} Q \cdot C \cdot \mathrm{d} t
$$

式中, $M$ 为时段 $T$ 内通过断面的 TN、TP 通量, $\mathrm{t} ; Q$ 为瞬时流量, $\mathrm{m}^{3} / \mathrm{s} ; C$ 为 TN 或 TP 瞬时浓度, $\mathrm{mg} / \mathrm{L}$. 由于浓 度 $C$ 一般无连续实测资料, 故目前通量计算一般采用的是 Webb 等 ${ }^{[21]}$ 构建的 5 种时段通量估算公式计算, 但估算结果往往受采样时机和采样频率的影响较大, 特别是未考虑泥沙对污染物的影响. 考虑到华弹站、向 家坝站 $\mathrm{TN} / Q 、 \mathrm{TP} / \mathrm{Q}$ 与含沙量 $\mathrm{S}$ 的相关性相对较好, 且两站均有连续实测的逐日流量、逐日含沙量数据, 故 采用式 (1) 来插补缺测日的 TN、TP 浓度不失为一种可行的方法. 以年为单位, 对式 (2) 以日为尺度进行差 分,得年通量计算公式为:

$$
M=k \sum_{i=1}^{365}\left(Q_{i} \cdot C_{i}\right)
$$

式中, $Q_{i}$ 为某年第 $i$ 日通过断面的流量; $C_{i}$ 为第 $i$ 日通过断面的 TN、TP 浓度; $k$ 为换算系数, $k=0.0864$.

将式(1) 代人式 (3)，即得 TN、TP 年通量计算公式为:

$$
M=k \cdot a \sum_{i=1}^{365}\left(S_{i}^{b} \cdot Q_{i}^{2}\right)
$$

式中, $S_{i}$ 为某年第 $i$ 日的含沙量, $\mathrm{kg} / \mathrm{m}^{3}$.

由表 5 可见,华弹站 TN 年通量在 48357 135827 t 之间变化, TP 年通量在 $4720 \sim 14163 \mathrm{t}$ 之间变化,年均 值分别为 90337 和 $8932 \mathrm{t}$. 向家坝站蓄水前、后 TN 年通量在 64232 130966 和 71675 149647 t 之间变化, 年 均值分别为 88004 和 $107602 \mathrm{t}$, 蓄水后通量总体大于蓄水前; TP 年通量在 $8851 \sim 18624$ 和 $3131 \sim 7300 \mathrm{t}$ 之间 变化,年均值分别为 11715 和 $4762 \mathrm{t}$, 蓄水后通量远小于蓄水前,约减少了 $59.4 \%$. 前面分析表明,溪洛渡、向 家坝水库蓄水后, 向家坝站的泥沙通量较蓄水前约减少了 $98.7 \%, \mathrm{TP}$ 通量减少率低于泥沙通量减少率, 主要 是因为水质检测的样品为澄清样,已去除掉了一部分泥沙.

为分析计算成果的合理性,根据金沙江下游污染来源、水流变化等情况,选用 Webb 等提出的“方法 D” 公式 ${ }^{[21]}$ 重新估算了两站蓄水前后 $\mathrm{TN} 、 \mathrm{TP}$ 的年通量,与本文估算的结果进行对比,结果见图 6. 总体来看,两 种方法的计算成果无显著性差异. 由于本文方法不但考虑到了径流对污染物的作用,还考虑了泥沙对污染 物的影响, 其计算成果可能更符合实际情况. 但限于资料的缺陷, 目前还无法验证, 有待于以后收集逐日水 
质监测资料, 以检验本文计算方法的可靠性.

表 5 蓄水前后华弹站、向家坝站总氮和总磷年通量

Tab.5 Fluxes of total nitrogen and total phosphorus at Huatan and Xiangiaba Stations before and after storage

\begin{tabular}{|c|c|c|c|c|c|c|c|c|c|c|c|c|}
\hline \multirow{2}{*}{ 水文站 } & \multirow{2}{*}{ 指标 } & \multicolumn{7}{|c|}{ 蓄水前年通量/t } & \multicolumn{4}{|c|}{ 蓄水后年通量/t } \\
\hline & & 2006 年 & 2007 年 & 2008 年 & 2009 年 & 2010 年 & 2011 年 & 2012 年 & 2013 年 & 2014 年 & 2015 年 & 2016 年 \\
\hline \multirow[t]{2}{*}{ 华弹 } & $\mathrm{TN}$ & 48357 & 69075 & 108891 & 94216 & 79817 & 60265 & 119913 & 77491 & 135827 & 84408 & 115454 \\
\hline & TP & 4720 & 6437 & 10417 & 8773 & 7528 & 6195 & 11541 & 7897 & 14163 & 8641 & 11942 \\
\hline \multirow[t]{2}{*}{ 向家坝 } & $\mathrm{TN}$ & 64232 & 73486 & 90857 & 103346 & 81316 & 71825 & 130966 & 71675 & 105232 & 149647 & 103856 \\
\hline & $\mathrm{TP}$ & 8851 & 9363 & 11154 & 13750 & 10429 & 9837 & 18624 & 3131 & 4219 & 7300 & 4398 \\
\hline
\end{tabular}

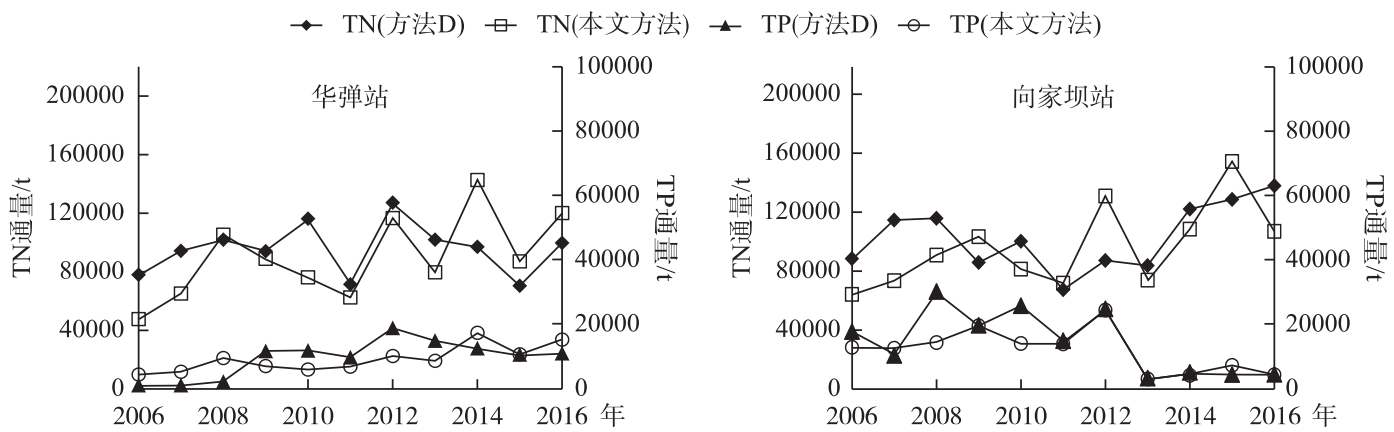

图 6 两种方法计算的总氮和总磷逐年通量

Fig.6 Annual average fluxes of total nitrogen and total phosphorus calculated by two methods

2.4.2 梯级水库对 TN、TP 的滞留效应 水库对 $\mathrm{TN} 、 \mathrm{TP}$ 通量的滞留效应采用再祥滨的方法 ${ }^{[22]}$ 计算:

$$
R E T=\left(M_{\text {in }}-M_{\text {out }}\right) / M_{\text {in }}
$$

式中, RET 为通量的滞留率; $M_{\mathrm{in}}$ 为人库通量, $\mathrm{t}, M_{\text {out }}$ 为出库通量, $\mathrm{t}$. 溪洛渡、向家坝梯级水库人库通量包括金 沙江干流华弹站人库通量和华弹至向家坝区间的人库通量. 由于蓄水后区间人库通量尚无调查成果, 故采 用蓄水前向家坝站与华弹站通量之差近似估算.

根据表 5 计算得到的蓄水前华弹站和向家坝站 TN、TP 年均通量,推算得蓄水前华弹至向家坝区间 TN 年均人库通量为 $5071 \mathrm{t}, \mathrm{TP}$ 人库通量为 $3771 \mathrm{t}$, 由此计算得蓄水后 TN 和 TP 年均总人库通量分别为 108366 和 $14431 \mathrm{t}$. 将梯级水库进出库 TN 和 TP 年均通量代人公式 (5), 得到 TN 和 TP 通量的实际滞留率分别为 0.7\% 和 67.0\%. TN 滞留率远远小于 TP, 其差异实质上是氮、磷的滞留机理不同造成的. 对氮而言, 主导机制 是脱氮反应 ${ }^{[23]}$, 在水库对氮的滞留中, 脱氮反应受到水流停留时间、氮负荷等因素的影响, 尤其是水流停留 时间. 水库可以延长水流停留时间, 在一定程度上增加氮的去除, 不过在陆地表层水体氮循环过程中, 脱氮 反应总量巨大, 由此从整个流域范围来看, 水库滞留效应产生的改变有限 ${ }^{[24]}$. 对于磷而言, 主导机制为颗粒 态磷的沉降, 这是由于水体中的磷主要以颗粒态存在, 水库蓄水后, 由于水深增加, 流速减少, 大量颗粒态磷 发生沉降, 造成水体中磷元素显著减少, 此外生物对磷酸盐的吸收与转化作用也加剧了库区水体对磷的滞 留效应. 当水体的水环境发生改变后, 库区底泥中的部分磷元素又会重新释放到水体中, 这一过程与水体的 $\mathrm{pH}$ 值、温度、紊动强度以及底泥的组成等条件有关, 本文暂不讨论.

\section{3 结论}

通过对金沙江下游华弹站、向家坝站 2006-2016 年水文、水质资料的整理、归纳与分析,得到下列结论:

1) 华弹站 TN 和 TP 浓度在 $0.38 \sim 1.41$ 和 $0.01 \sim 0.73 \mathrm{mg} / \mathrm{L}$ 之间变化, 蓄水前后无明显差异; 向家坝站蓄 水前 $\mathrm{TN}$ 和 $\mathrm{TP}$ 浓度在 $0.32 \sim 1.33$ 和 $0.03 \sim 0.42 \mathrm{mg} / \mathrm{L}$ 之间变化, 蓄水后 $\mathrm{TN}$ 浓度总体较蓄水前升高, 但 $\mathrm{TP}$ 浓 
度较蓄水前降低约 75\% . 金沙江 $\mathrm{TN}$ 形态以 $\mathrm{NO}_{3}^{-}-\mathrm{N}$ 为主, 占 $\mathrm{TN}$ 浓度的 $67.3 \% \sim 91.8 \%$.

2) 华弹站和向家坝站 TN、TP 浓度总体表现为汛期高于枯季. 受水库拦截的影响, 向家坝站 TP 浓度较 蓄水前大幅降低,其中洪水期减少率明显高于平水期和枯水期.

3 ) 蓄水前金沙江下游 TN 浓度沿程变化不大, TP 浓度沿程升高, 但蓄水后 TN 的浓度沿程升高, TP 浓度 受泥沙淤积影响, 沿程明显降低.

4) 建立了 $\mathrm{TN} / \mathrm{Q} 、 \mathrm{TP} / \mathrm{Q}$ 与含沙量 $\mathrm{S}$ 的相关关系, 以此关系可插补缺测日的 TN、TP 浓度, 一定程度上避 免了水质监测测次偏少给通量计算带来的困难.

5 ) 华弹站 TN 和 TP 年通量在 48357 135827 和 4720 14163 t 之间变化,年均分别为 90337 和 $8932 \mathrm{t}$, 向 家坝站蓄水前后 $\mathrm{TN}$ 年通量在 $64232 \sim 130966$ 和 $71675 \sim 149647 \mathrm{t}$ 之间变化, 蓄水后通量总体大于蓄水前, TP 年通量在 $8851 \sim 18624$ 和 $3131 \sim 7300 \mathrm{t}$ 之间变化, 蓄水后通量远小于蓄水前.

6) 水库蓄水对出库 TN 浓度与通量无明显影响,但 TP 浓度与通量较蓄水前明显降低,其中通量年均滞 留率约为 $67.0 \%$. 需指出的是, 当水体的水环境发生改变后, 库区底泥中的部分磷又会重新释放到水体中, 其滞留效应将发生改变.

\section{4 参考文献}

[ 1 ] Syvitski JPM, Vorosmarty C, Kettner AJ et al. Impact of human on the flux of terrestrial sediment to the global coastal ocean. Science, 2005, 308(5720) : 376-380.

[ 2 ] Bennekom VAJ, Salomons W. Pathways of nutrients and organic matter from load to ocean through rivers. In: Martine JM, Burton JD, Esima D eds. Rivers inputs to ocean system. Rome: UNEP/UNESCO, 1981: 33-35.

[ 3 ] Josette G, Gilles B, Michel C. Seasonal succession of diatoms and Chlorophyceae in the in the drainage network of the network of the Seine River: Observations and modeling. Limnology \& Oceangraphy, 1995, 40(4) : 750-765.

[ 4 ] Ouyang W, Skidmore AK, Toxopeus AG et al. Long-term vegetation landscape pattern with non-point source nutrient pollution in upper stream of Yellow River basin. Journal of Hydrology, 2010, 389(3/4) : 373-380.

[ 5 ] Zhou JJ, Zhang M, Lu P. The effect of dams on phosphorus in the middle and lower Yangtze River. Water Resource Research, 2013, 49: 3659-3669.

[ 6 ] Hu CH, Zhou WB, Zhong XL et al. Retention of nitrogen and phosphorus in Wan'an Reservoir, Jiangxi Provin. J Lake Sci, 2011, 23(1) : 35-39. DOI: 10.18307/2011.0106. [胡春华, 周文斌, 钟夏莲等. 江西省万安水库对氮、磷营养盐的 滞留效应. 湖泊科学, 2011, 23(1) : 35-39.]

[ 7 ] Zhou T, Cheng TY, Yu NX et al. Nitrogen and phosphorus retention in cascade reservoirs along the upper reaches of Wujiang river. Chinese Journal of Ecology, 2018, (3) : 707-713. [ 周涛, 程天雨, 虞宁晓等. 乌江中上游梯级水库氮磷 滞留效应. 生态学杂志, 2018, (3) : 707-713.]

[ 8 ] Xu QX, Tong H. Characteristics of flow and sediment change in Yangtze River in recent 50 years. Journal of China Hydrol$o g y, 2012,(5): 38-46$. [许全喜, 童辉. 近 50 年来长江水沙水沙变化规律研究. 水文, 2012, (5): 38-46.]

[ 9 ] Shen ZL. Preliminary study on the Changjiang River mainstream nutrients fluxes. Oceanologia et Limnologia Sinica, 1997, (5) : 522-527. [沈志良. 长江干流营养盐通量的初步研究. 海洋与湖泊, 1997, (5) :522-527. ]

[10] Zhu LL, Chen CH, Zhang JS. Study on variations ofrunoff and sediment and effect to the lower Jinsha River. Journal of Sediment Research, 2016, (5) : 20-27. [ 朱玲玲, 陈翠华, 张继顺. 金沙江下游水沙变异及其宏观效应研究. 泥沙研 究, 2016, (5) : 20-27.]

[11] Wang YG, Shi HL, Liu X. Influence of sediment trapping in reservoirs on runoff and sediment discharge variation in Yangtze River. Advance in Water Science, 2014, (4) : 468-475. [王延贵, 史红玲, 刘茜. 水库拦沙对长江水沙态势变化 的影响. 水科学进展, 2014, (4): 467-475.]

[12] Guo ZF, Gao YC, Deng QY et al. Water quality situation of Xiangjiaba reservoir in Jinsha river. Yangtze River, 2009, (3) : 31-34. [ 郭宗锋, 高一川, 邓卿艳等. 金沙江向家坝库区段水质现状. 人民长江, 2009, (3): 31-34.]

[13] Chen SS, Zhang OY, Chen ZF et al. Variation of runoff and sediment load of Jinsha River. Advance in Water Science, 2008, (4) : 475-482. [陈松生, 张欧阳, 陈泽方等. 金沙江流域不同区域水沙变化特征及原因分析. 水科学进展, 2008 , (4) : 475-482.] 
[14] Liu H, Chen QB, Wang KQ et al. Soil erosion properties in typical section of Dry-Hot valley of Jinsha basin. Journal of Soil and Water Conservation, 2012, (5) : 28-33. [刘海, 陈奇伯, 王克勤等. 金沙江干热河谷典型区段水土流失特 征. 水土保持学报, 2012, (5) : 28-33.]

[15] Huang Q, Zhao XH et al eds. Theory and method of time series analysis and prediction of river runoff. Zhengzhou: The Yellow River Water Conservancy Press, 2008. [黄强, 赵雪花等. 河川径流时间序列分析预测理论与方法. 郑州: 黄 河水利出版社, 2008.]

[16] Duan SW, Zhang S. The variations of nitrogen and phosphorus concentrations in the monitoring stations of the three major rivers in China. Scientia Geographica Sinica, 1999, (5): 411-416. [段水旺, 章申. 中国主要河流控制站氮、磷含量变 化规律初探. 地理科学, 1999, (5) : 411-416.]

[17] Meybeck M. Carbon, nitrogen and phosphorus transport by world rivers. Science of Total Environment. 2000, 282: 401-450

[18] Yu XZ, Liao WG, Lv PY et al eds. Study on the effect of sediment on main pollutants in the Three Gorges Reservoir area. Beijing: Science Press, 2010. [ 禹雪中, 廖文根, 吕平毓. 三峡库区泥沙对主要污染物作用研究. 北京: 科学出版 社, 2010.]

[19] Zhou JJ, Zhang M, Li Z. Dams altered Yangtze River phosphorus and restoration countermeasures. J Lake Sci, 2018, 30 (4) : 865-880. DOI: 10.18307/2018.0401. [ 周建军, 张曼, 李哲. 长江上游水库改变干流磷通量、效应与修复对策. 湖泊科学. 2018, 30(4): 865-880.]

[20] Shao XJ, Wang XK eds. River dynamics. Beijing: Tsinghua University Press, 2013. [邵学军, 王兴奎. 河流动力学概 论. 北京: 清华大学出版社, 2013.]

[21] Webb BW, Phillips JM, Walling DE et al. Load estimation methodologies for British rivers and their relevance to the Loisracs Programme. Science of Total Environment, 1997, 96: 379-389.

[22] Ran XB. Nutrient distributions and retention of the Three Gorges Reservoir [Dissertation]. Qingdao: Ocean University of China, 2009. [ 由祥滨. 三峡水库营养盐分布特征与滞留效应研究 [ 学位论文]. 青岛: 中国海洋大学, 2009.]

[23] Jossette G, Leporcq B, Sanchez N et al. Biogeochemical mass-balances ( C, N, P, Si) in three large reservoir of Seine basin (France). Biogeochemistry, 1999, (2) : 119-146.

[24] Ran XB, Yu ZG, Yao QZ et al. Advance in nutrient retention of dams on river. J Lake Sci, 2009, 21( 5) : 614-622. DOI: 10.18307/2009.0502. [ 由祥滨, 于志刚, 姚庆祯等. 水库对河流营养盐滞留效应研究进展. 湖泊科学, 2009,21 (5) : 614-622.] 